\title{
White light emission of Mn-doped SnO-ZnO-P_2O_5 glass containing no rare earth cation
}

\section{AUTHOR(S):}

Masai, Hirokazu; Fujiwara, Takumi; Matsumoto, Syuji; Takahashi, Yoshihiro; Iwasaki, Kenichiro; Tokuda, Yomei; Yoko, Toshinobu

\section{CITATION:}

Masai, Hirokazu ...[et al]. White light emission of Mn-doped SnO-ZnO-P_20_5 glass containing no rare earth cation. Optics Letters 2011, 36(15): 2868-2870

\section{ISSUE DATE:}

2011-07-25

URL:

http://hdl.handle.net/2433/145987

RIGHT:

(C) 2011 Optical Society of America. 


\title{
White light emission of Mn-doped $\mathrm{SnO}-\mathrm{ZnO}-\mathrm{P}_{2} \mathrm{O}_{5}$ glass containing no rare earth cation
}

\author{
Hirokazu Masai, ${ }^{1, *}$ Takumi Fujiwara, ${ }^{2}$ Syuji Matsumoto, ${ }^{3}$ Yoshihiro Takahashi, ${ }^{2}$ \\ Kenichiro Iwasaki, ${ }^{2}$ Yomei Tokuda, ${ }^{1}$ and Toshinobu Yoko ${ }^{1}$ \\ ${ }^{1}$ Institute for Chemical Research, Kyoto University, Gokasyo, Uji, Kyoto 611-0011, Japan \\ ${ }^{2}$ Department of Applied Physics, School of Engineering, Tohoku University, 6-6-05 Aoba, Sendai 980-8579, Japan \\ ${ }^{3}$ Research Center, Asahi Glass Co. Ltd., 1150 Hazawa-cho, Kanagawa-ku, Yokohama 211-8755, Japan \\ *Corresponding author: masai_h@noncry.kuicr.kyoto-u.ac.jp \\ Received June 10, 2011; revised June 30, 2011; accepted June 30, 2011; \\ posted June 30, 2011 (Doc. ID 148989); published July 25, 2011 \\ The authors have demonstrated white light emission of rare earth (RE)-free Mn-doped SnO- $\mathrm{ZnO}_{2} \mathrm{P}_{2} \mathrm{O}_{5}$ glass. The RE- \\ free glass shows white light emission with a high value of quantum efficiency (QE) comparable to conventional \\ crystalline phosphor. It is notable that the high QE value is attained for RE-free transparent glass, and the broad \\ emission can be continuously tuned by both the amount of activator and the composition of the glass. Since this \\ glass possesses low-melting property, we emphasize that the glass phosphor will lead to the development of a novel \\ inorganic white-light-emitting device in combination with a solid state UV light-emitting source. (C) 2011 Optical \\ Society of America \\ OCIS codes: $\quad 160.2750,160.2540,160.4670$.
}

Currently, optical materials containing trivalent rare earth (RE) cations have been widely used. These RE cations possess a $4 \mathrm{f}-4 \mathrm{f}$ transition that is hardly affected by the surrounding crystal field, which is characterized by narrow band emission. The strong, sharp emission of RE cation has also been used for white-emitting devices, such as the three narrow emission band type of white fluorescent lamp or the white LED [1]. However, these devices consisting of sharp emission bands possess lower color rendering than the conventional broadband emission device. In addition, RE-free material is favorable from the viewpoint of the uneven distribution of $\mathrm{RE}$ on earth. Since the study of phosphor has been supported by advances in LEDs [2-5], a novel phosphor for next-generation LED will be required.

For these reasons, the authors have emphasized that white light emission, constituted of various kinds of wavelengths, can be attained by a RE-free phosphor, for example $\mathrm{Sb}^{3+}, \mathrm{Mn}^{2+}$-doped calcium halophosphate [6]. Although the emission of the phosphor generally possesses two broad emission bands, these emission bands are inherently fixed because of the crystal structure [7]. On the other hand, if glass material without the RE cation shows white light emission comparable to the crystalline phosphor, it will be considered a novel emitting material capable of much broader emission and good formability that is quite important in the industrial manufacturing process. In general, oxide glass has a great ability to incorporate various kinds of atoms; therefore, the coordination fields of the emission center and the resulting emission color can be tuned. Such emitting material is quite different from the conventional RE-doped crystalline phosphor.

In the study, we have focused on the $\mathrm{ns}^{2}$-type emission center as an activator. Since the $\mathrm{ns}^{2}$-type emission centers $(n \geqq 4)$ possess an electron in the outermost shell in both the ground state $\left(\mathrm{ns}^{2}\right)$ and the excited state $\left(n s^{1} \mathrm{np}^{1}\right.$ ), the emission is strongly affected by the coordination field $[1,8-11]$. Therefore, this type of emission center is suitable for amorphous glass, in which site distribution is much broader than that in crystal. Recently, the authors of this study reported the highest quantum efficiency (QE) for amorphous SnO-ZnO- $\mathrm{P}_{2} \mathrm{O}_{5}$ low-melting glass [12]. It is notable that the transparent glass containing no RE cation shows a high UV-excited emission that is comparable to a crystal phosphor such as $\mathrm{MgWO}_{4}$; further, this was the largest efficiency of glass material without RE cation ever reported. The emission is brought about by $\mathrm{Sn}^{2+}$, which is the most conventional and harmless $\mathrm{ns}^{2}$-type center [13-16]. Moreover, the emission property of the obtained glass remains unchanged after heat treatment at forming temperature regions, which indicates that the obtained glass is suitable for low-melting glass that can be applied as the sealing material of an LED $[17,18]$. Since the previous glass showed broad blue emission [12], it is expected that white light emission can be attained by the addition of $\mathrm{Mn}^{2+}$ cation, similar to the $\mathrm{Sb}^{3+}, \mathrm{Mn}^{2+}$-codoped calcium halophosphate.

The present $\mathrm{MnO}-\mathrm{SnO}-\mathrm{ZnO}-\mathrm{P}_{2} \mathrm{O}_{5}$ glass was prepared according to a conventional melt-quenching method that employs a platinum crucible. Batches consisting of $\mathrm{ZnO}$ and $\left(\mathrm{NH}_{4}\right)_{2} \mathrm{HPO}_{4}$ were first heat treated at $300^{\circ} \mathrm{C}$ for $1 \mathrm{~h}$ and $800{ }^{\circ} \mathrm{C}$ for $3 \mathrm{~h}$ to remove $\mathrm{NH}_{3}$ and residual $\mathrm{OH}$ groups. The heat-treated glass precursor was mixed with $\mathrm{SnO}$ and $\mathrm{MnO}$ and then melted at $1100^{\circ} \mathrm{C}$ for $30 \mathrm{~min}$ at ambient atmosphere. The glass melt was quenched on a steel plate at $200^{\circ} \mathrm{C}$ and then annealed at the glass transition temperature, $T_{g}$, as measured by differential thermal analysis, for $1 \mathrm{~h}$. The photoluminescent (PL) and PL excitation (PLE) spectra were measured at room temperature (r.t.). The emission decay at r.t. was measured using a Quantaurus-Tau (Hamamatsu Photonics) with a $280 \mathrm{~nm}$ LED. The absolute $\mathrm{QE}$ of the glass was measured using an integrating sphere (Hamamatsu Photonics C9920-02) at r.t. The $\mathrm{QE}$ was evaluated using the normalized $\mathrm{QE}$ (NQE) that was obtained by normalization of practical phosphor $\mathrm{MgWO}_{4}$ excited by a wavelength of $254 \mathrm{~nm}$. The NQE was calculated using 
Table 1. Chemical Composition of the $\mathrm{MnO}-\mathrm{SnO}-\mathrm{ZnO}-\mathrm{P}_{2} \mathrm{O}_{5}$ Glasses and the $\mathrm{NQE}^{a}$

\begin{tabular}{cccccccc}
\hline \multicolumn{3}{c}{ Composition (mol. \%) } & & \multicolumn{3}{c}{ CCP } & \\
\cline { 1 - 3 } $\mathrm{Mnn}$ & $\mathrm{SnO}$ & $\mathrm{ZnO}$ & $\mathrm{P}_{2} \mathrm{O}_{5}$ & $\mathrm{NQE}( \pm 1 \%)$ & $x$ & $y$ & Color \\
\hline 0.00 & 2.5 & 57.5 & 40.0 & 0.84 & 0.22 & 0.26 & $\square$ \\
0.10 & 2.5 & 57.5 & 40.0 & 0.99 & 0.23 & 0.27 & $\square$ \\
0.25 & 2.5 & 57.5 & 40.0 & 0.93 & 0.25 & 0.28 & $\square$ \\
0.50 & 2.5 & 57.5 & 40.0 & 0.95 & 0.28 & 0.30 & $\square$ \\
0.70 & 2.5 & 57.5 & 40.0 & 0.90 & 0.31 & 0.31 & $\square$ \\
1.00 & 2.5 & 57.5 & 40.0 & 0.91 & 0.34 & 0.32 & $\square$ \\
2.00 & 2.5 & 57.5 & 40.0 & 0.97 & 0.42 & 0.34 & $\square$ \\
0.25 & 2.5 & 62.5 & 35.0 & 0.87 & 0.25 & 0.26 & $\square$ \\
0.25 & 2.5 & 60.0 & 37.5 & 0.91 & 0.25 & 0.26 & $\square$ \\
0.25 & 2.5 & 55.0 & 42.5 & 0.99 & 0.25 & 0.29 & $\square$ \\
0.50 & 2.5 & 62.5 & 35.0 & 0.90 & 0.29 & 0.28 & $\square$ \\
0.50 & 2.5 & 60.0 & 37.5 & 0.94 & 0.28 & 0.28 & $\square$ \\
0.50 & 2.5 & 55.0 & 42.5 & 0.98 & 0.28 & 0.30 & $\square$ \\
\hline
\end{tabular}

${ }^{a}$ Their chromatic coordination positions (CCPs) and colors under excitation (4.88 eV; $254 \mathrm{~nm}$ ) are also shown.

$$
\mathrm{NQE}=P_{g} \Delta E_{s} / P_{s} \Delta E_{g},
$$

where $P_{g}$ and $P_{s}$ are the area intensity of glass and the standard phosphor $\mathrm{MgWO}_{4}$, respectively, $\Delta E_{s}$ is the absorption of $\mathrm{MgWO}_{4}$ at $254 \mathrm{~nm}$, and $\Delta E_{g}$ is the photon number absorbed by the sample, which was obtained by the difference between the area intensity of blank $E_{g 0}$ and that of sample $E_{g 1}$.

Table 1 shows the chemical composition of the obtained glasses. These glasses were transparent and colorless. The $T_{g}$ of these glasses was less than $440^{\circ} \mathrm{C}$, as they belong to the so-called "low-melting glass," whose manufacturing temperature is below $600^{\circ} \mathrm{C}$. Figure 1 shows the PL spectra of the $x \mathrm{MnO}-2.5 \mathrm{SnO}-57.5 \mathrm{ZnO}-40 \mathrm{P}_{2} \mathrm{O}_{5}$ glass excited by the photon energy of $4.88 \mathrm{eV}(254 \mathrm{~nm})$. The value of $x$ (mol. \%) shows the additive amount of $\mathrm{MnO}$. The composition consists of $\mathrm{MnO}$ and the glass composition that showed the maximum $\mathrm{QE}$ in the previous report [12]. These emission spectra consist of two broad bands of the $\mathrm{Sn}^{2+}$ emission center $(2.86 \mathrm{eV})$ and $\mathrm{Mn}^{2+}$ center [19] $(2.05 \mathrm{eV})$. It is expected that the $\mathrm{Sn}^{2+}$ center plays roles both in the emission center and in the energy donor. The lifetimes $\left(\tau_{1 / e}\right)$ of the $\mathrm{Sn}$

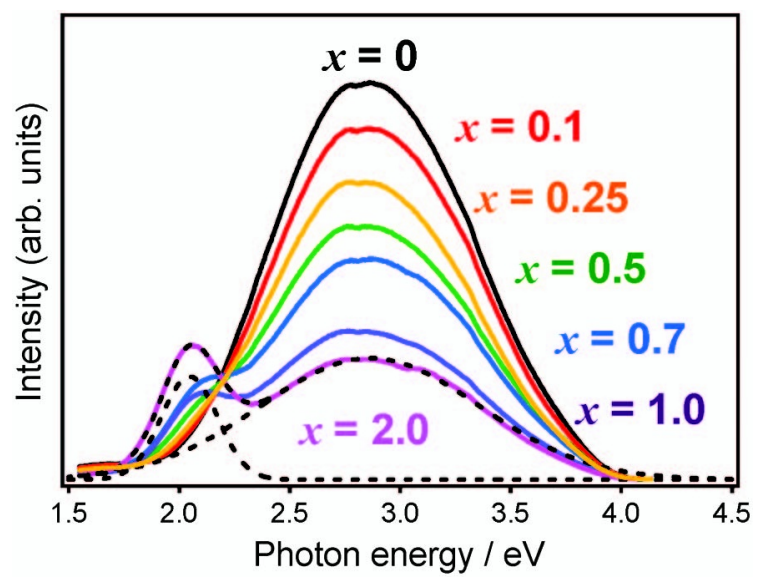

Fig. 1. Correlation between PL intensity excited by $4.88 \mathrm{eV}$ and the amount of $\mathrm{Mn}$ in the $x \mathrm{MnO}-2.5 \mathrm{SnO}-57.5 \mathrm{ZnO}-40 \mathrm{P}_{2} \mathrm{O}_{5}$ glasses. emission $(2.86 \mathrm{eV})$ of the nondoped glass $(x=0)$ and Mn-doped glass $(x=2.0)$ are $4.5 \mu \mathrm{s}$ and $2.1 \mu \mathrm{s}$, respectively. The change can be explained by the energy transfer using the Dexter's theory [20]. Peak deconvolution revealed that these two peaks showed little change in the emission band and the half-width, indicating that local coordination of $\mathrm{Sn}^{2+}$ and $\mathrm{Mn}^{2+}$ was hardly affected by the concentration of $\mathrm{MnO}$.

Figure 2 shows PL and PLE spectra of the $0.5 \mathrm{MnO}-2.5 \overline{\mathrm{S} n O}-y \mathrm{ZnO}-(97.5-y) \mathrm{P}_{2} \mathrm{O}_{5}$ glasses $(y=55.0$, $57.5,60.0$, and 62.5). Although the concentrations of the activators were equal in both glasses, the glass containing the larger amount of $\mathrm{ZnO}$ exhibited a slightly narrower PLE peak and a smaller Stokes shift. The observed peak shift is due to the difference of coordination field of the $\mathrm{Sn}^{2+}$ emission center, and the emission band of $\mathrm{Mn}^{2+}$ is almost independent of the composition. It clearly shows that the $\mathrm{ns}^{2}$-type $\mathrm{Sn}^{2+}$ emission center is affected by the coordination field. The so-called theoretical basicity of the glass increases with increasing amounts of $\mathrm{ZnO}$ [21]; it can thereby be said that the Stokes shift becomes smaller by increasing the optical basicity of the glass. On the other hand, Duffy and Ingram [22] determined the optical basicity of the glass using the experimentally measured peak frequency of the ${ }^{1} S_{0} \rightarrow{ }^{3} P_{1}$ transition of $\mathrm{Tl}^{+}, \mathrm{Bi}^{3+}$, and $\mathrm{Pb}^{2+}$. Although they reported no data concerning $\mathrm{Sn}^{2+}, \mathrm{ns}^{2}$-type $\mathrm{Sn}^{2+}$ can also serve as a probe for estimation of the basicity. The observed peak shift indicates that optical basicity also increased qualitatively by the addition of $\mathrm{ZnO}$. With an increasing amount of $\mathrm{ZnO}$, the PL peak was blueshifted to increase the emission in the UV region. Thus, there was an increase in the relative intensity of red color that was attributed to the emission from $\mathrm{Mn}^{2+}$.

Figure 3 shows chromatic coordination mapping of the SnO-ZnO- $\overline{\mathrm{P}}_{2} \mathrm{O}_{5}$ glasses. The inset shows a photograph of the glass phosphors $(x=0,0.7,2.0)$ with and without UV light $(254 \mathrm{~nm})$. The NQE values and color coordination position of the samples are shown in Table 1. It is notable that these glasses show a high NQE value comparable to that of practical $\mathrm{MgWO}_{4}$, whose $\mathrm{QE}$ value was reported to be greater than $80 \%$. This value enables us to confirm the potential application of the present RE-free glass as phosphor with a high NQE. On the other hand, it is also noteworthy that the color coordination positions are

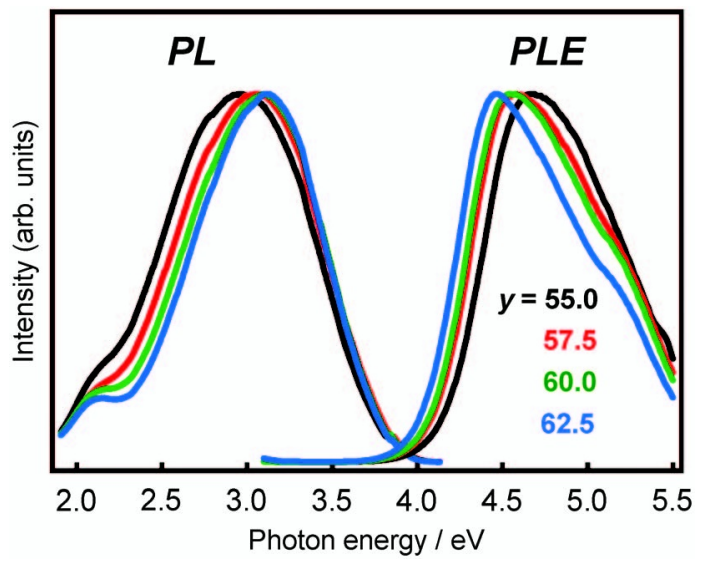

Fig. 2. PL and PLE spectra of 0.5MnO-2.5SnO-yZnO$(97.5-y) \mathrm{P}_{2} \mathrm{O}_{5}$ glasses. 


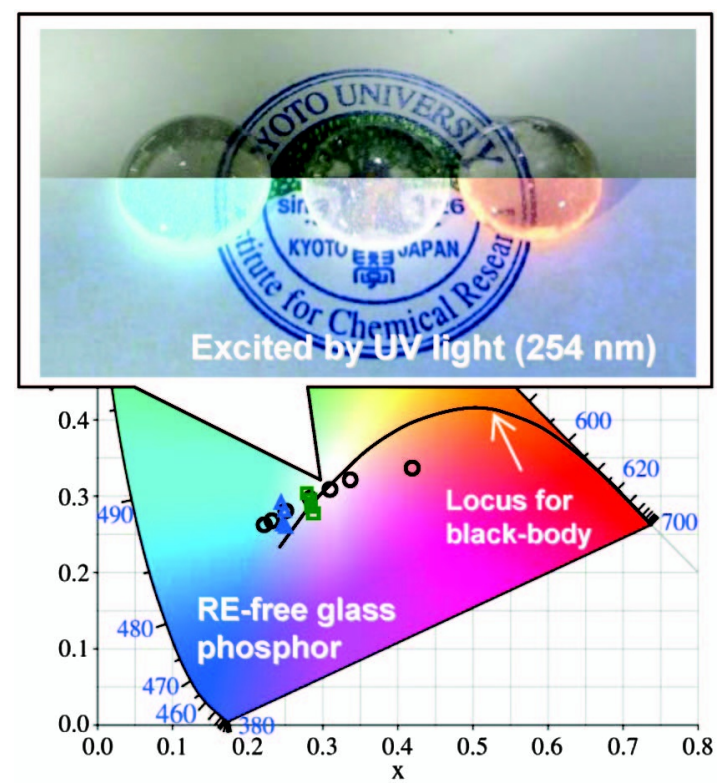

Fig. 3. Chromatic coordination mapping of the $\mathrm{SnO}-\mathrm{ZnO}-\mathrm{P}_{2} \mathrm{O}_{5}$ glasses excited by the photon energy of $4.88 \mathrm{eV}(254 \mathrm{~nm})$. Black circles: $x \mathrm{MnO}-2.5 \mathrm{SnO}-57.5 \mathrm{ZnO}-40 \mathrm{P}_{2} \mathrm{O}_{5}$. Green squares: $0.5 \mathrm{MnO}-2.5 \mathrm{SnO}-(97.5-y) \mathrm{ZnO}-y \mathrm{P}_{2} \mathrm{O}_{5}$. Blue triangles: $0.25 \mathrm{MnO}$ 2.5SnO-(97.5- $z) \mathrm{ZnO}-z \mathrm{P}_{2} \mathrm{O}_{5}$. Inset shows photograph of the glass phosphors $(x=0,0.7,2.0)$ with and without UV light $(254 \mathrm{~nm})$.

continuously changed from blue to red with the addition of $\mathrm{MnO}$. In particular, several glasses satisfy the white light emission condition without the RE cation. The emission from $\mathrm{Sn}^{2+}$ in the glass showed the maximum PL peak around $420 \mathrm{~nm}$, which is about $60 \mathrm{~nm}$ shorter than that of $\mathrm{Sb}^{3+}$-doped calcium halophosphate, and therefore no additional blue phosphor was needed to improve the color rendering. This is also a notable advantage of the present $\mathrm{Sn}^{2+}$-doped glass phosphor.

From the obtained results, it is suggested that the basicity of the glass affects both the emission center and the following emission color. Since the basicity of oxide glasses is tailored by a great variety of chemical compositions, the emission color is also controlled in a wide range. The present results indicate that the Mn-doped SnO-ZnO- $\mathrm{P}_{2} \mathrm{O}_{5}$ glass will be (1) a novel PL material that does not contain an RE cation, which is a benefit for natural resources, (2) a candidate for conventional organic sealant that is damaged by strong UV light, and (3) a novel white LED in combination with deep-UV LED. Although the present glass shows white light emission that is similar to halo calcium phosphate crystal, there are several large differences between the two. First, for a greater number of emission centers, $\mathrm{Sn}^{2+}$ can be doped in glass. Second, various kinds of elements can be added to the glass to control the emission properties as well as to improve the mechanical or thermal property. Third, monolithic material can reduce optical loss due to scattering at the interface. Moreover, transparent emission material will meet novel industrial applications. Since organic material as well as an organic-inorganic hybrid cannot be used for deep-UV light sources, inorganic low-melting materials will be important in these applications.

$\mathrm{RE}$ cations generally exhibit a high $\mathrm{QE}$ value because there is little influence of phonons. We have emphasized that the present RE-free amorphous glass possesses high QE values comparable to RE-doped crystalline phosphor, although it shows a broad emission tunable by the local coordination state. Although we have not yet clarified the mechanism, the present $\mathrm{ns}^{2}$-type center appears to be very advantageous from the viewpoint of unique emission mechanisms in a random matrix: the coexistence of high efficiency and broad emission. Recent development of a deep-UV LED [5] clearly suggests a possibility for Hg-free white fluorescent lamps in the near future. RE-free inorganic amorphous materials possessing emission properties by excitation of a UV LED source will be required for the novel practical optical device.

\section{References}

1. W. M. Yen, S. Shionoya, and H. Yamamoto, Phosphor Handbook, 2nd ed. (CRC, 2007).

2. S. Nakamura, T. Mukai, and M. Senoh, Jpn. J. Appl. Phys. Lett. 30, L1998 (1991).

3. M. C. Schmidt, K.-C. Kim, H. Sato, N. Fellows, H. Masui, S. Nakamura, S. P. Denbaars, and J. S. Speck, Jpn. J. Appl. Phys. 46, L126 (2007).

4. H. Hirayama, N. Noguchi, and N. Kamata, Appl. Phys. Express 3, 032102 (2010).

5. T. Oto, R. G. Banal, K. Kataoka, M. Funato, and Y. Kawakami, Nat. Photon. 4, 767 (2010).

6. A. Wachtel, J. Electrochem. Soc. 113, 128 (1966).

7. K. H. Butler and C. W. Jerome, J. Electrochem. Soc. 97, 265 (1950).

8. R. C. Ropp and R. W. Mooney, J. Electrochem. Soc. 107, 15 (1960).

9. T. S. Davis, E. R. Kreidler, J. A. Parodi, and T. F. Soules, J. Lumin. 4, 48 (1971).

10. M. Leskelä, T. Koskentalo, and G. Blasse, J. Solid State Chem. 59, 272 (1985).

11. R. H. Clapp and R. J. Ginther, J. Opt. Soc. Am. 37, 355 (1947).

12. H. Masai, Y. Takahashi, T. Fujiwara, S. Matsumoto, and T. Yoko, Appl. Phys. Express 3, 082102 (2010).

13. L. Skuja, J. Non-Cryst. Solids 149, 77 (1992).

14. T. Hayakawa, T. Enomoto, and M. Nogami, Jpn. J. Appl. Phys. 45, 5078 (2006).

15. T. Akai and K. Kadono, "Transparent white fluorescent glass," U. S. patent WO 2007017928-A1 (Aug. 8, 2005).

16. J. G. Hooley, "Fluorescent glass composition," U. S. patent 2,400,147 (May 14, 1946).

17. S. Matsumoto, N. Nakamura, and N. Wada, "Glass, coating material for light-emitting device, and light-emitting device,” U. S. patent WO 2009/088086 (Jan. 9, 2009).

18. S. Matsumoto, Y. Osaki, and N. Nakamura, "Glass for optical device covering, glass-covered light-emitting element, and glass-covered light-emitting device," U. S. patent WO 2008/146886 (May 29, 2008).

19. K. H. Butler, J. Electrochem. Soc. 100, 250 (1953).

20. D. L. Dexter, J. Chem. Phys. 21, 836 (1953).

21. J. A. Duffy and M. D. Ingram, J. Non-Cryst. Solids 21, 373 (1976).

22. J. A. Duffy and M. D. Ingram, J. Am. Chem. Soc. 93, 6448 (1971). 